\title{
Postpartum vitamin A supplementation for HIV-positive women is not associated with mortality and morbidity of their breastfed infants: evidence from multiple national surveys in sub-Saharan Africa
}

Samson Gebremedhin(1)

\begin{abstract}
Background: Vitamin A supplementation (VAS) in the postpartum period improves the vitamin A concentration of breast milk and vitamin A status is an important predictor of childhood survival. It is also known that Vitamin A Deficiency (VAD) is more prevalent in HIV-infected women. This study investigated the association between vitamin A supplements provided to HIV-positive women in the postpartum period and mortality and morbidity of their breastfed infants in sub-Saharan Africa (SSA) where the prevalence of VAD and HIV is high.

Methods: This cross-sectional study was conducted based on the secondary data of 838 HIV-positive women (309 vitamin A supplement and 529 non-supplemented) extracted from the datasets of 43 Demographic and Health Surveys (DHS) conducted in 26 SSA countries between 2003 and 2015. The data of HIV-positive women who gave a live birth in the preceding 6 months of the survey and who were breastfeeding their infants at the time of the survey or who breastfed their deceased infants until the time of death, were included in the analysis. The association of postpartum VAS with early infant mortality (death in the first 6 months of birth) and morbidity secondary to fever, diarrhoea and cough with respiratory difficulties in the preceding 2 weeks was assessed by mixed-effects logistic regression model and interpreted using adjusted odds ratio (AOR) with the $95 \%$ confidence intervals (CI).

Results: About one-third (36.9\%) of the HIV-positive women received VAS soon after the recent delivery. The early infant mortality rate per 1000 live births in vitamin A supplemented group was 100 (95\% Cl: 67-133) and the corresponding level for non-supplemented group was 125 (95\% Cl: 97-154). Yet, in the multivariable model adjusted for seven potential confounders, the association was not significant (AOR $=1.10$ : 95\% Cl, 0.572.13). Similarly, postpartum VAS was not significantly associated with the occurrence of cough with difficult breathing $(A O R=0.65: 95 \% \mathrm{Cl}, 0.39-1.10)$, diarrhoea $(A O R=0.89: 95 \% C l, 0.50-1.58)$ and fever $(A O R=1.19: 95 \%$ Cl 0.78-1.82) in their breastfed infants.

(Continued on next page)
\end{abstract}

Correspondence: samsongmgs@yahoo.com

School of Public Health, Addis Ababa University, Addis Ababa, Ethiopia

(c) The Author(s). 2020 Open Access This article is licensed under a Creative Commons Attribution 4.0 International License, which permits use, sharing, adaptation, distribution and reproduction in any medium or format, as long as you give appropriate credit to the original author(s) and the source, provide a link to the Creative Commons licence, and indicate if changes were made. The images or other third party material in this article are included in the article's Creative Commons licence, unless indicated otherwise in a credit line to the material. If material is not included in the article's Creative Commons licence and your intended use is not permitted by statutory regulation or exceeds the permitted use, you will need to obtain permission directly from the copyright holder. To view a copy of this licence, visit http://creativecommons.org/licenses/by/4.0/. The Creative Commons Public Domain Dedication waiver (http://creativecommons.org/publicdomain/zero/1.0/) applies to the data made available in this article, unless otherwise stated in a credit line to the data. 
(Continued from previous page)

Conclusion: VAS provided to HIV-positive women in the immediate postpartum period does not have significant association with the mortality and morbidity of their breastfed infants.

Keywords: Vitamin a supplementation, HIV, Infant mortality, Fever, Diarrhoea, Cough, Lactation, Demographic and health surveys, Sub-Saharan Africa

\section{Background}

Vitamin A deficiency (VAD) is a major public health problem in many low- and middle-income countries. Globally more than 120 countries have moderate or severe public health significance of VAD as measured by biochemical insufficiency in pre-school children [1]. Globally, low serum retinol concentration affects 33\% of children and 15\% of pregnant women. Especially SouthEast Asia and sub-Saharan Africa (SSA) regions have the highest burden of VAD [1]. Established consequences of VAD among young children include increased risk of mortality and severity of infections, blindness, growth retardation and anemia [1]. Similarly, during pregnancy VAD predisposes to anemia, clinical infections and night blindness [2].

Vitamin A supplementation (VAS) is a proven, quick and low-cost strategy for correcting vitamin A status of populations [3]. Systematic reviews of randomized controlled trials suggested beyond doubt that in children 659 months of age, VAS reduces all-cause mortality by $25 \%$ and significantly diminishes occurrence of diarrhoea, measles and xeropthalmia [4, 5]. Furthermore, neonatal VAS may marginally reduce 6-month infant mortality in setting where the magnitude of VAD is high [6]. In many low-income countries routine VAS is already in place for combating the deficiency in preschool children and lactating women. Children 6-59 months receive biannual and high dose (100,000-200, 000 International Unit (IU)) supplements and lactating women are provided with a single 200,000 IU supplement within 6 weeks postpartum.

In women, breastfeeding increases the requirement for vitamin $\mathrm{A}$ and the amount lost through lactation may predispose to maternal VAD [7]. In the first 6 months of life, breastfed infants consume more than $300 \mu \mathrm{mol}$ of vitamin A from the mother's milk [8]. Breast milk vitamin A concentration is sensitive to maternal dietary intake and in the situation of inadequate intake, the infant may not get enough in the breast milk [9]. Convincing evidence exists that single high dose VAS (60-120 mg retinol equivalent) after giving births improves the retinol concertation of breast milk at 3-3.5 months postpartum [9]. Yet, systematic reviews have suggested that supplement provided in the first 6 weeks of birth does not significantly reduce maternal and infant mortality and morbidity $[9,10]$.
HIV/AIDS remains a major global public health threat. In 2018 about 38 million people were living with HIV and the SSA is the most seriously affected region accounting for approximately $70 \%$ of the existing cases $[11,12]$. Complex relationship exists between malnutrition and HIV infection. HIV compromises nutrition through multiple pathways including reducing appetite, causing malabsorption of nutrients, altering metabolism and increasing the demand for essential nutrients. Further, HIV-related immune impairment may predispose to secondary malnutrition. Advanced HIV infection causes wasting syndrome and compromises economic productivity and food security [13, 14]. HIV infection increases energy requirements by 10 to $30 \%$ depending on the stage of progression of the infection [15].

It has been reported that VAD is more common in HIV-infected women than in uninfected women [1618]. Further, a couple of studies witnessed increased mortality of infants born to vitamin A-deficient HIVpositive mothers $[19,20]$. Consequently, this study explored whether receipt of VAS by HIV-positive women in the postpartum period is associated with reduction in mortality and morbidity of their breastfed infants or not. The study was conducted based on the secondary data of multiple Demographic and Health Surveys (DHS) carried out in SSA region where the magnitudes of VAD, HIV-infection and infant mortality are all high. In general, at the beginning of the study it was hypothesized that postpartum VAS to HIV-positive women would be associated with reduced mortality and morbidity of their breastfed infants based on the following propositions (i) HIV-positive women and their new-borns are at increased risk of VAD [16-18]; (ii) postpartum VAS improves vitamin A concentration of breast milk [9]; and (iii) vitamin A reduces the risk of child mortality and morbidity in settings where VAD is prevalent $[4,5]$.

\section{Methods \\ Study design}

This cross-sectional observational study was conducted based on the secondary data of 43 DHS carried out in 26 SSA countries between 2003 and 2015. Demographic and Health Surveys are nationally-representative household cross-sectional surveys being implemented on regular basis in many low- and middle-income countries by national agencies with the support of the Measure-DHS 
Program. The surveys are intended to provide updated information on a wide range of population and health indicators. In many countries the DHS are typically implemented in 5 years interval.

Pertaining to the inclusion and exclusion criteria, the geographical scope of the study was delimited to the SSA region considering the fact that VAD, HIVinfection and infant mortality are all highly prevalent in the sub-continent. In the surveys conducted before 2003 and after 2015, HIV status and postpartum VAS-related data respectively, had not been collected in women of reproductive age (15-49 years); thus, the surveys were excluded from the study. The list of the surveys considered eligible for the analysis is provided as a supplementary file (Supplementary file 1).

The datasets of the 43 surveys were accessed from the Measure DHS website (https://dhsprogram.com/data/) and the information about non-eligible subjects (HIVnegative women, women who have no information about HIV and VAS status and those who did not give birth within 6 months of the survey) was dropped. Ultimately, the data of 838 HIV-positive women who gave live birth in the preceding 6 months, who have clear information about their postpartum VAS exposure status and who were breastfeeding their infants at the time of the survey (or until the death of their deceased infants) retained in the analysis (Fig. 1).

For each eligible subject relevant information including VAS status, survival status of the infant, age at death for deceased infants, occurrence of diarrhoea, fever and cough with shortness of/difficult breath (proxy for acute respiratory infection (ARI)) in the preceding 15 days of the survey, basic socio-demographic characteristics and other potential confounders including access to massmedia, health service utilization, types of drinking water source and household sanitary facility, maternal anthropometry were extracted.

\section{Sample size and power}

As the study was conducted based secondary data, sample size determination has not been made. Yet, post-hoc power calculation indicated, the available sample size of 838 HIV-positive women - comprising 309 vitamin A supplement and 529 non-supplemented subjects - is

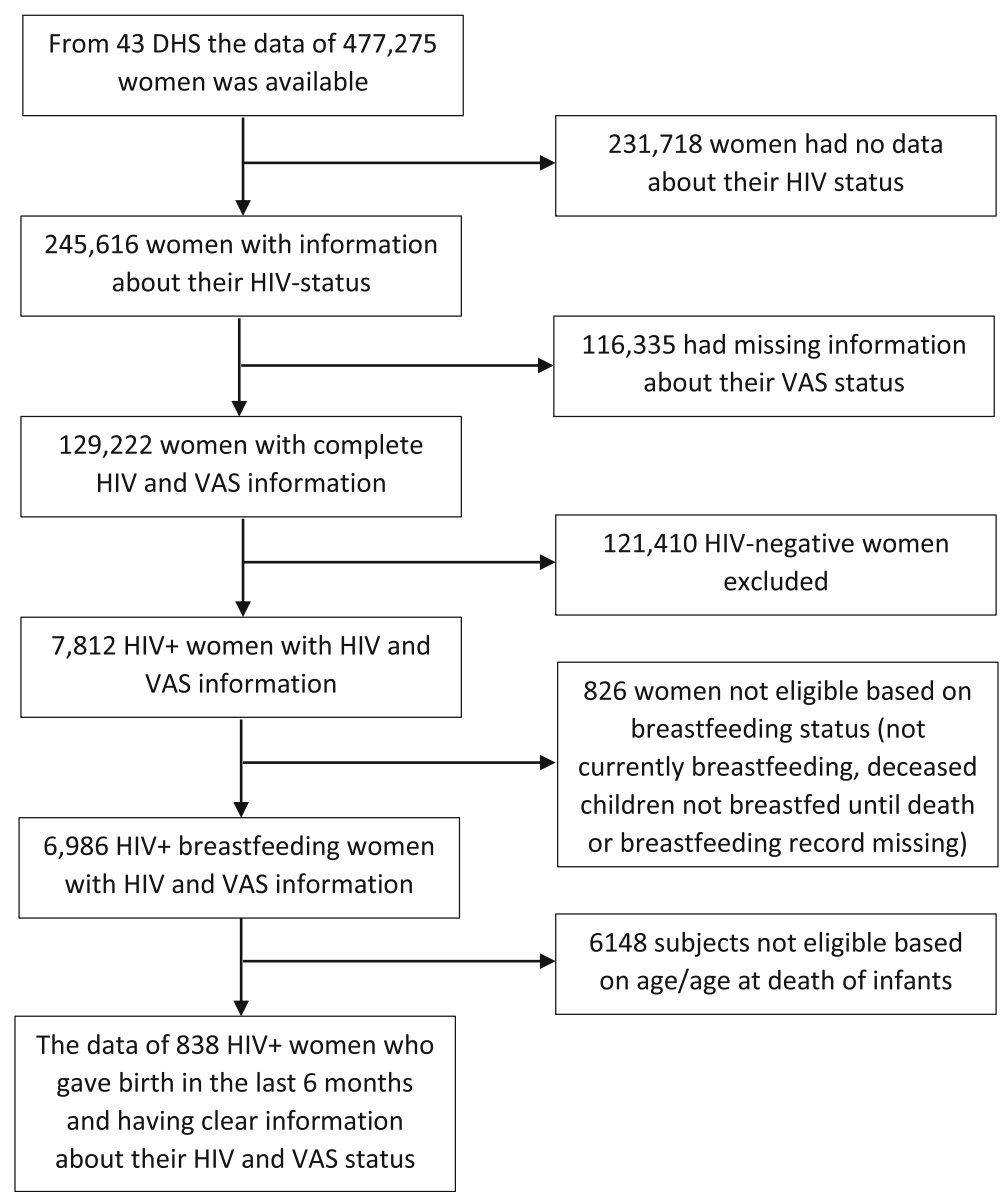

Fig. 1 Flow chart of the study 
sufficient to detect $6 \%$ difference in early infant mortality (death in the first 6 months of birth) between the two group with approximately $80 \%$ power and $95 \%$ confidence level. The post-hoc power calculation was made assuming that the early Infant Mortality Rate (IMR) in non-supplemented group is 125 per 1000 live births.

\section{Sampling approach of DHS}

Demographic and Health Surveys are designed to generate representative data at national and sub-national (region or state) levels and typically use a two-stage cluster sampling approach for recruiting the study participants. At the first stage, a sample of Enumeration Areas (EAs) stratified by sub-national regions and place of residence (urban, rural) is selected with probability proportional to size approach. In the selected EAs an exhaustive listing of households is performed. At the second stage, a predetermined 20 to 30 households is selected by systematic sampling approach. In each selected household, all eligible subjects including women of reproductive age are identified, interviewed and blood samples for HIV testing are collected [21].

\section{Data collection procedures of DHS}

In the original surveys, data were collected from the respondents by trained interviewers using standardized and pretested questionnaires prepared in the major local languages of the respective host countries. Maternal receipt vitamin A supplement in the post-partum period was assessed by showing a vitamin A capsule to the study participant and asking whether she had taken the same soon after the recent delivery or not. The occurrence of diarrhoea, fever and cough with shortness or difficult breath was assessed by asking one-by-one if the index infant had the same problem in the preceding 2 weeks of the survey without any further clinical evaluation. Breastfeeding practice was assessed by asking whether the mother breastfed her child in the preceding day of the survey or not, irrespective of frequency or amount of breastfeeding.

Maternal height and weight were measured using calibrated tools, body-mass-index (BMI) was computed using the standard formula and women were classified as thin $\left(\mathrm{BMI}<18.5 \mathrm{~kg} / \mathrm{m}^{2}\right.$ ), normal (BMI between 18.5 and $\left.24.9 \mathrm{~kg} / \mathrm{m}^{2}\right)$ or overweight/obese $\left(B M I>25 \mathrm{~kg} / \mathrm{m}^{2}\right)$. Birthweight of the infants were determined based on recall of the mothers and classified as low $(<2.5 \mathrm{~kg})$, normal $(2.5-3.9 \mathrm{~kg})$ or macrosomic $(4.0$ or above $\mathrm{kg})$ birthweight.

\section{Data management and analysis}

The datasets of the 43 surveys were downloaded from the Measure DHS website in SPSS format and merged into one spreadsheet. Irrelevant variables and data of non-eligible subjects were dropped and the remaining data got cleaned and recoded as needed. The dataset analysed is provided as a supporting file (Supplementary file 2).

Data were analysed using weight analysis approach on the basis of the sample weights readily available in the datasets. Data were presented using appropriate measures of central tendency and dispersion, frequency distributions and tables. Wealth index, a composite index of living standard, was determined based on ownership of valuable household assets (such as television, radio and mobile phone), materials used for housing construction (type of floor, wall and roof) and types of water source and sanitation facility. The analysis was made using Principal Component Analysis, ultimately a factor with the highest explained variability based on eigenvalue of 1 was identified and was categorized into wealth quintiles (poorest, poorer, middle, richer, richest). Wealth index was determined separately for each survey and pooled into one from all surveys.

The association of postpartum VAS with early infant mortality and infant morbidity secondary to fever, diarrhoea and ARI-related symptoms in the preceding 2 weeks was assessed using mixed-effects bivariable and multivariable logistic regression models with random slope for each country. Separate models were developed for each of the aforementioned four outcome variables. The vitamin A supplemented and non-supplemented groups were initially compared based on multiple sociodemographic, health service utilization and access to mass media-related variables using Pearson's Chi-square test. Variable that were found to be significantly unbalanced ( $p$-value $<0.05)$ or marginally unbalanced ( $p$-value between 0.2 and 0.05 ) were considered as potential confounders; thus, got adjusted in the multivariable models. The fitness of the multivariable models was assessed using Hosmer and Lemeshow test. Interpretation was made by exponentiating the logistic regression coefficients into crude (COR) and adjusted (AOR) odds ratios.

\section{Ethical consideration}

The datasets were downloaded after securing permission from the Measure DHS Program. For this specific secondary data analysis ethical clearance was not sought. Nevertheless, all the original DHS protocols were reviewed and approved by the Demographic and Health Survey Program, ICF International Inc., Institutional Review Board.

\section{Results}

Basic characteristics of the respondents

The data of 838 HIV-positive women who gave live birth in the preceding 6 months were included in the analysis. About one-third (309 (36.9\%)) of the mothers received vitamin A supplement after the recent birth; whereas, 
the remaining two-thirds (529 (63.1\%)) did not. Most of the study subjects (70.2\%) were from the southern Africa region and smaller proportions $(<10 \%)$ were drawn from the eastern or central parts of Africa.

Nearly two-thirds (64.8\%) of the respondents were selected from male-headed households and $40.5 \%$ were from households of richer or richest wealth quintiles. The mean ( \pm standard deviation) age of the respondents was $27.9( \pm 6.0)$ years and about half $(52.3 \%)$ were between 25 to 34 years of age. About two-fifths (41.4\%) had secondary or post-secondary education and $64.0 \%$ resided in rural areas. Three-quarters (73.4\%) were married or living together with their partners. Nearly twothirds of the women had normal BMI $\left(18.5-24.9 \mathrm{~kg} / \mathrm{m}^{2}\right)$.

Table 1 compares the geographic distribution, basic socio-demographic characteristics, anthropometric characteristics, patterns of health service utilization and access to mass media between vitamin A supplemented and nonsupplemented groups using chi-square test. In terms of socio-demographic characteristics, the two groups were balanced $(p>0.05)$ in most of the characteristics including source of drinking water and household sanitation facility. However, infants born to vitamin A supplemented women were significantly older than their counterparts $(2.9 \pm 1.6$ mos vs $2.6 \pm 1.7$ mos $)(P=0.017)$. Regarding, utilization of preventive health services, women who were vitamin A supplemented had better utilization of health facility delivery, postnatal care and childhood vaccination services $(P<0.001)$. Significant different in the patten of birthweight was also observed between the two groups $(p=$ 0.001). No meaningful differences were observed in terms of access to mass media including frequency of watching television and listening to radio (Table 1 ).

\section{Maternal vitamin a supplementation and survival of breastfed infants}

The early infant mortality rate (eIMR) in the entire HIVpositive subjects included in the analysis was 116 (95\% CI: 94-137) per 1000 live births. The mortality rate in vitamin A supplemented group was 100 (95\% CI: 67-133) and the corresponding rate for non-supplemented group was 125 (95\% CI: 97-154) per 1000 live births. However, in the multivariable model that adjusted for seven potential confounders (geographic region of the country, place of delivery, utilization of postnatal care, sex of the newborn, type of household sanitation facility, number of under five children in the household and frequency of watching television) the association was not statistically significant $(\mathrm{AOR}=1.10: 95 \% \mathrm{CI}, 0.57-2.13)$ (Table 2).

\section{Maternal vitamin a supplementation and morbidity of breastfed infants}

Table 3 presents the association between maternal vitamin A supplementation in HIV-positive women and occurrence of diarrhoea, fever and ARI-related symptoms in their breastfed offspring younger than 6 months of age. Among infants of women who received VAS soon after birth, 9.1\% of had cough with shortness/difficulty of breath in the preceding 2 weeks of the survey and the corresponding figure was $12.3 \%$ in the infants born to non-supplemented women. However, in the multivariable model adjusted for nine potential confounders (geographic region of the country, place of delivery, utilization of postnatal care, sex of the newborn, type of household sanitation facility, number of under five children in the household, frequency of watching television, age of the child and vaccination status of the child), the difference was marginally insignificant $\quad(\mathrm{AOR}=0.65: \quad 95 \% \quad \mathrm{CI}, \quad 0.39-1.10) \quad(p=0.108)$. Likewise, maternal VAS was not associated with reduced odds of diarrhoea (AOR $=0.89: 95 \% \mathrm{CI}, 0.50-1.58)(p=$ $0.681)$ and fever $(\mathrm{AOR}=1.19: 95 \%$ CI $0.78-1.82)(p=$ 0.777) (Table 3).

\section{Discussion}

This study based on secondary data of multiple DHS conducted in SSA countries, found no statistically significant association between vitamin A supplement provided to HIV-positive women in the postpartum period and, mortality and morbidity from fever, diarrhoea ARIrelated symptoms among their breastfed infants.

Vitamin A plays a critical role in the proliferation, regulation and reaction to stimuli of immunocompetent cells [22]. Based on the established knowledge that postpartum VAS improves breastmilk vitamin A concentration $[9,23,24]$ and vitamin A status is an important predictor of childhood survival [5], one may deduct that supplement provided to women in the postpartum period boosts the survival of their breastfed infants. Intuitively, the intervention may even seem to be more beneficial to infants born to HIV-positive women because such cases are more liable to VAD [16-18]. However, this study did not come across with such findings. Likewise, a systematic review of three trials conducted in Tanzania, Malawi and Zimbabwe concluded that VAS provided to HIV-positive women during pregnancy or in the postpartum period had no benefit of reducing IMR [25]. Similarly, a systematic review of 14 trials that were not limited to HIV-positive women found no association between postpartum maternal VAS and survival their infants [9].

The unexpected lack of association between postpartum VAS and infant mortality can be explained by a couple of reasons. First, though there is convincing evidence that VAS improves the vitamin A concertation in breast milk, the change in concentration is likely to be modest [9] or may not be sustained beyond the first three or 4 months of supplementation [9, 26-28]. 
Table 1 Basic characteristics of HIV-positive women included in the analysis, Sub-Saharan Africa, 2003-2015

\begin{tabular}{|c|c|c|c|c|c|c|c|}
\hline \multirow[t]{3}{*}{ Variables $(\boldsymbol{n}=838)$} & \multicolumn{4}{|c|}{ Vitamin A supplemented } & \multirow{2}{*}{\multicolumn{2}{|c|}{$\begin{array}{l}\text { Both } \\
(\boldsymbol{n}=838)\end{array}$}} & \multirow[t]{3}{*}{$\boldsymbol{P}$-value } \\
\hline & \multicolumn{2}{|c|}{ Yes $(\boldsymbol{n}=309)$} & \multicolumn{2}{|c|}{ No $(\boldsymbol{n}=529)$} & & & \\
\hline & Freq & $\%$ & Freq & $\%$ & Freq & $\%$ & \\
\hline \multicolumn{8}{|l|}{ Sub-Saharan Africa Region } \\
\hline Eastern & 10 & 3.4 & 52 & 9.9 & 63 & 7.5 & \multirow[t]{4}{*}{$<0.001^{*}$} \\
\hline Southern & 232 & 74.8 & 357 & 67.4 & 588 & 70.2 & \\
\hline Western & 57 & 18.5 & 86 & 16.2 & 143 & 17.0 & \\
\hline Central & 10 & 3.3 & 35 & 6.5 & 45 & 5.3 & \\
\hline \multicolumn{8}{|l|}{ Sex of the household head } \\
\hline Male & 193 & 62.5 & 350 & 66.1 & 543 & 64.8 & \multirow[t]{2}{*}{0.279} \\
\hline Female & 116 & 37.5 & 179 & 33.9 & 295 & 35.2 & \\
\hline \multicolumn{8}{|l|}{ Household wealth index } \\
\hline Poorest or poorer & 123 & 39.6 & 206 & 38.9 & 328 & 39.1 & \multirow[t]{3}{*}{0.755} \\
\hline Middle & 59 & 19.1 & 112 & 21.2 & 171 & 20.4 & \\
\hline Richer or richest & 128 & 41.3 & 211 & 40.0 & 339 & 40.5 & \\
\hline \multicolumn{8}{|l|}{ Maternal age (years) } \\
\hline $15-24$ & 105 & 33.9 & 162 & 30.6 & 267 & 31.8 & \multirow[t]{3}{*}{0.611} \\
\hline $25-34$ & 157 & 50.7 & 282 & 53.2 & 438 & 52.3 & \\
\hline 35 or above & 48 & 15.4 & 86 & 16.2 & 133 & 15.9 & \\
\hline \multicolumn{8}{|l|}{ Marital status } \\
\hline Never in union & 54 & 17.4 & 72 & 13.6 & 126 & 15.0 & \multirow[t]{4}{*}{0.388} \\
\hline Married/living with partner & 217 & 70.2 & 398 & 75.2 & 615 & 73.4 & \\
\hline Widowed & 11 & 3.5 & 18 & 3.4 & 29 & 3.5 & \\
\hline Divorced or separated & 28 & 8.9 & 41 & 7.8 & 69 & 8.2 & \\
\hline \multicolumn{8}{|l|}{ Place of residence } \\
\hline Urban & 117 & 37.9 & 184 & 34.9 & 302 & 36.0 & \multirow[t]{2}{*}{0.380} \\
\hline Rural & 192 & 62.1 & 344 & 65.1 & 537 & 64.0 & \\
\hline \multicolumn{8}{|l|}{ Maternal education } \\
\hline No formal education & 53 & 17.2 & 75 & 14.2 & 128 & 15.3 & \multirow[t]{3}{*}{0.469} \\
\hline Primary education & 134 & 43.4 & 229 & 43.4 & 364 & 43.4 & \\
\hline Secondary or higher education & 122 & 39.5 & 224 & 42.4 & 347 & 41.3 & \\
\hline \multicolumn{8}{|c|}{ Number of children under the age of 5 years } \\
\hline 0 & 17 & 5.4 & 48 & 9.0 & 65 & 7.7 & \multirow[t]{3}{*}{0.108} \\
\hline 1 & 121 & 39.0 & 182 & 34.4 & 303 & 36.1 & \\
\hline 2 or more & 172 & 55.5 & 299 & 56.6 & 471 & 56.2 & \\
\hline \multicolumn{8}{|l|}{ Maternal body-mass-index $\left(\mathrm{kg} / \mathrm{m}^{2}\right)$} \\
\hline$<18.5$ & 22 & 7.3 & 31 & 5.9 & 53 & 6.4 & 0.407 \\
\hline $18-5-24.9$ & 200 & 64.8 & 369 & 69.8 & 569 & 67.9 & \\
\hline 25 or above & 80 & 25.8 & 122 & 23.1 & 202 & 24.1 & \\
\hline Missing & 7 & 2.2 & 7 & 1.3 & 14 & 1.6 & \\
\hline Sex of the child & & & & & & & \\
\hline Boy & 158 & 51.2 & 239 & 45.1 & 397 & 47.4 & 0.096 \\
\hline Girl & 151 & 48.8 & 290 & 54.9 & 441 & 52.6 & \\
\hline Age of the index child (months) ( $n$ & & & & & & & \\
\hline $0-1$ & 61 & 21.6 & 156 & 34.1 & 217 & 29.4 & $0.001^{*}$ \\
\hline
\end{tabular}


Table 1 Basic characteristics of HIV-positive women included in the analysis, Sub-Saharan Africa, 2003-2015 (Continued)

\begin{tabular}{|c|c|c|c|c|c|c|c|}
\hline \multirow[t]{3}{*}{ Variables $(\boldsymbol{n}=838)$} & \multicolumn{4}{|c|}{ Vitamin A supplemented } & \multirow{2}{*}{\multicolumn{2}{|c|}{$\begin{array}{l}\text { Both } \\
(\boldsymbol{n}=838)\end{array}$}} & \multirow[t]{3}{*}{$\boldsymbol{P}$-value } \\
\hline & \multicolumn{2}{|c|}{ Yes $(\boldsymbol{n}=309)$} & \multicolumn{2}{|c|}{ No $(\boldsymbol{n}=529)$} & & & \\
\hline & Freq & $\%$ & Freq & $\%$ & Freq & $\%$ & \\
\hline $2-3$ & 112 & 39.6 & 139 & 30.6 & 251 & 34.0 & \\
\hline $4-5$ & 109 & 38.7 & 161 & 35.3 & 270 & 36.6 & \\
\hline \multicolumn{8}{|l|}{ Birth weight as reported by the mother } \\
\hline$<2.5 \mathrm{~kg}$ & 36 & 11.5 & 32 & 6.0 & 68 & 8.0 & $0.001^{*}$ \\
\hline $2.5-3.9 \mathrm{~kg}$ & 188 & 60.9 & 290 & 54.8 & 478 & 57.1 & \\
\hline $4.0 \mathrm{~kg}$ or above & 12 & 4.0 & 26 & 4.9 & 38 & 4.6 & \\
\hline Not weighted at birth or don't know & 73 & 23.6 & 181 & 34.3 & 254 & 30.3 & \\
\hline \multicolumn{8}{|l|}{ Drinking water source } \\
\hline Improved & 221 & 71.3 & 372 & 70.4 & 593 & 70.7 & 0.766 \\
\hline Unimproved & 89 & 28.7 & 157 & 29.6 & 246 & 29.3 & \\
\hline \multicolumn{8}{|l|}{ Sanitation facility } \\
\hline Improved & 144 & 27.3 & 99 & 31.9 & 243 & 29.0 & 0.146 \\
\hline Unimproved & 385 & 72.7 & 211 & 68.1 & 595 & 71.0 & \\
\hline \multicolumn{8}{|l|}{ Place of delivery } \\
\hline Home & 71 & 23.1 & 191 & 36.1 & 262 & 31.3 & $<0.001^{*}$ \\
\hline Health facility & 238 & 76.9 & 338 & 63.9 & 576 & 68.7 & \\
\hline \multicolumn{8}{|c|}{ Any postnatal check-up by health professional } \\
\hline No & 150 & 48.4 & 391 & 73.8 & 540 & 64.4 & $<0.001^{*}$ \\
\hline Yes & 160 & 51.6 & 138 & 26.2 & 298 & 35.6 & \\
\hline \multicolumn{8}{|l|}{ Child ever vaccinated $(n=737)^{\times}$} \\
\hline No & 35 & 11.4 & 119 & 22.4 & 154 & 20.9 & $<0.001^{*}$ \\
\hline Yes & 246 & 79.6 & 337 & 63.8 & 583 & 79.1 & \\
\hline \multicolumn{8}{|l|}{ Frequency of watching TV } \\
\hline Not at all & 188 & 60.9 & 354 & 67.0 & 543 & 64.7 & 0.181 \\
\hline Less than once a week & 35 & 11.3 & 46 & 8.6 & 81 & 9.6 & \\
\hline At least once a week & 86 & 27.7 & 129 & 24.4 & 215 & 25.6 & \\
\hline \multicolumn{8}{|l|}{ Frequency of listening to radio } \\
\hline Not at all & 110 & 35.6 & 165 & 31.2 & 275 & 32.8 & 0.409 \\
\hline Less than once a week & 49 & 15.8 & 86 & 16.3 & 135 & 16.1 & \\
\hline At least once a week & 150 & 48.6 & 278 & 52.5 & 428 & 51.1 & \\
\hline${ }^{\times}$excluding deceased infants & & & & & & & \\
\hline
\end{tabular}

Accordingly, it probably makes little or no contribution included in study were all breastfeeding during the surto infants' survival. Further, even though the infants veys, or were breastfed until death, the DHS data

Table 2 Association between maternal vitamin A supplementation and early infant mortality in HIV-positive women, sub-Saharan Africa

\begin{tabular}{|c|c|c|c|c|c|c|}
\hline \multirow{3}{*}{$\begin{array}{l}\text { Vitamin A supplementation } \\
\text { status }\end{array}$} & \multicolumn{4}{|c|}{ Survival status } & \multicolumn{2}{|l|}{ Odds ratio } \\
\hline & \multicolumn{2}{|c|}{ Deceased } & \multicolumn{2}{|l|}{ Alive } & \multirow[t]{2}{*}{ Crude } & \multirow[t]{2}{*}{ Adjusted $^{a}$} \\
\hline & Freq & $\%$ & Freq & $\%$ & & \\
\hline Supplemented $(n=319)$ & 32 & 10.0 & 287 & 90.0 & $0.78(0.50-1.22)$ & $1.10(0.57-2.13)$ \\
\hline Non-supplemented $(n=519)$ & 65 & 12.5 & 454 & 87.5 & 1 & 1 \\
\hline
\end{tabular}

${ }^{a}$ Adjusted for geographic region of the country, place of delivery, utilization of postnatal care, sex of the newborn, type of household sanitation facility, number of under five children in the household and Frequency of watching television 
Table 3 Association between maternal vitamin A supplementation and occurrence of common childhood ailments in HIV-positive women, sub-Saharan Africa

\begin{tabular}{|c|c|c|c|c|c|c|}
\hline \multirow[t]{3}{*}{ Supplementation status } & \multicolumn{4}{|c|}{ Diarrhoea } & \multicolumn{2}{|c|}{ Odds ratio $(95 \% \mathrm{Cl})$} \\
\hline & \multicolumn{2}{|c|}{ Yes } & \multicolumn{2}{|l|}{ No } & \multirow[t]{2}{*}{ Crude } & \multirow[t]{2}{*}{ Adjusted $^{\mathrm{a}}$} \\
\hline & Freq & $\%$ & Freq & $\%$ & & \\
\hline Supplemented $(n=287)$ & 22 & 7.7 & 261 & 92.3 & $0.86(0.50-1.48)$ & $0.89(0.50-1.58)$ \\
\hline \multirow[t]{4}{*}{ Non-supplemented ( $n=454)$} & 40 & 8.8 & 414 & 91.2 & 1 & 1 \\
\hline & \multicolumn{4}{|c|}{ Fever } & & \\
\hline & Yes & & No & & & \\
\hline & Freq & $\%$ & Freq & $\%$ & & \\
\hline Supplemented $(n=287)$ & 56 & 19.5 & 231 & 80.5 & $1.23(0.84-1.80)$ & $1.19(0.78-1.82)$ \\
\hline \multirow[t]{4}{*}{ Non-supplemented ( $n=454)$} & 75 & 16.5 & 379 & 83.5 & 1 & 1 \\
\hline & \multicolumn{4}{|c|}{ ARI-related symptoms } & & \\
\hline & Yes & & No & & & \\
\hline & Freq & $\%$ & Freq & $\%$ & & \\
\hline Supplemented ( $n=287$ ) & 26 & 9.1 & 261 & 90.9 & $0.71(0.43-1.16)$ & $0.65(0.39-1.10)$ \\
\hline Non-supplemented $(n=454)$ & 56 & 12.3 & 398 & 87.7 & 1 & 1 \\
\hline
\end{tabular}

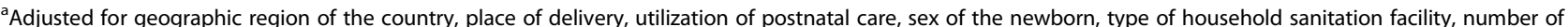
under five children in the household, frequency of watching television, age of the child and vaccination status of the child

provides no information about the intensity/frequency of breastfeeding and it is difficult to ascertain whether the infants had been receiving adequate vitamin A via breast milk or not.

The study suggested that VAS given to HIV-positive women in the immediate postpartum period has no association with infants' morbidity secondary to diarrhoea, fever or ARI-related symptoms. Very few studies have so far investigated the effect of postpartum VAS of HIVpositive women on the pattern of morbidity of their offspring. A randomized controlled trial conducted in Tanzania based on a large sample size $(n=1078)$ concluded that maternal receipt of vitamin A significantly reduced the risk of pneumonia, but had no effect on incidence of diarrhoea [29]. However, a systematic review of multiple trials conducted among apparently health women found no significant contribution of postpartum supplementation for reducing infants' morbidity [9].

The typical strength of this analysis is that, it is conducted based on the data of reasonably large number of HIV-positive women drawn from multiple SSA countries where VAD has moderate or severe public health significance. Further, considering the fact that the concentration of breast milk retinol becomes less responsive to VAS three or 4 months postpartum [26-28] and the amount of milk infants suck gradually declines after 6 months of age, the study was limited to breastfed infants younger than 6 months of age. We also attempted to control for multiple possible confounders via multivariable regression models.

Nevertheless, the study suffers from multiple methodological limitations. First, in terms of design, the ideal approach to address the research question is through randomized control trials. However, this study employed an observational cross-sectional design that is liable to systematic errors including information bias, selection bias and confounding from extraneous variables. Though we have attempted to adjust for multiple possible confounders via statistical approach, confounding from unmeasured variables or residual confounding due to imprecisely categorized or measured variables, cannot be entirely excluded.

As we used secondary data, it was not possible to account for some crucial variables that had not measured in in the original surveys including HIV status of the infants and progress/stage of the HIV infection in the women. Theoretically, HIV-positive infants and women with advanced HIV infection many benefit more from postpartum VAS than health individuals do. In addition, important information regarding the dosage and exact timing of supplementation was not available; consequently, the analysis was made based on the assumption that the women had received the usual single mega dose $(200,000$ international unit) supplementation in the first few days after delivery.

Though the study was conducted in SSA where VAD has huge public health significance, it does not mean that all the mother-baby dyads included in the analysis were actually deficient. Therefore, the analysis is liable to ecological fallacy and this could have underestimated the strength of association between the exposure and outcome. It is important to note that the findings cannot be directly generalized to vitamin A deficient HIVpositive women/infants because, at least theoretically, 
vitamin A deficient subjects are more likely to benefit from the supplement that those with unknown or normal vitamin A status do.

In this study the occurrence of fever, diarrhoea and ARI-related symptoms was only assessed based on selfreport of mothers without any supplementary clinical or laboratory investigation. Accordingly, this could have possibly caused misclassification bias and might have resulted in underestimation of the strength of association between the exposure and outcome. A study conducted in rural Bangladesh found that caregivers report has low sensitivity and specificity for diagnosing neonatal illness [30].

\section{Conclusion}

This secondary data analysis observed no statistically significant association between vitamin A supplementation provided to HIV-positive women in the postpartum period and occurrence early infant mortality and morbidity secondary diarrhoea, fever and ARI-related symptoms among their breastfed infants.

\section{Supplementary information}

Supplementary information accompanies this paper at https://doi.org/10. 1186/s12887-020-02131-8.

\section{Additional file 1.}

Additional file 2.

\section{Abbreviations}

AOR: Adjusted Odds Ratio; ARI: Acute Reparatory Infection; Cl: Confidence Intervals; COR: Crude Odds Ratio; DHS: Demographic and Health Surveys; EA: Enumeration Area; HIV: Human Immunodeficiency Virus; IRB: Institutional Review Board; IMR: Infant Mortality Rate; IU: International Unit; SPSS: Statistical Package for Social Science; SSA: Sub-Saharan Africa; VAS: Vitamin A Supplementation; VAD: Vitamin A Deficiency

\section{Acknowledgements}

The author acknowledges Measure DHS program for granting access to the datasets.

\section{Author's contributions}

SG analysed and interpreted the data and wrote the manuscript. The author(s) read and approved the final manuscript.

\section{Authors' information}

SG is an Associate Professor of Public Health at Addis Ababa University, Addis Ababa, Ethiopia.

\section{Funding}

No funding has been received for this study.

\section{Availability of data and materials}

All data generated or analysed during this study are included in this article.

\section{Ethics approval and consent to participate}

For this specific secondary data analysis ethical clearance was not sought. Nevertheless, all the original DHS were reviewed and approved by the Demographic and Health Survey Program, ICF International, Inc. Institutional Review Board.

\section{Consent for publication}

Not applicable.

\section{Competing interests}

The author declares that he has no competing interests. Samson Gebremedhin is an Associate Editor of BMC Pediatrics.

Received: 4 November 2019 Accepted: 6 May 2020

Published online: 13 May 2020

\section{References}

1. World Health Organization. Global prevalence of vitamin a deficiency in populations at risk 1995-2005 WHO global database on vitamin a deficiency. Geneva: World Health Organization; 2009.

2. McCauley ME, van den Broek N, Dou L, Othman M. Vitamin a supplementation during pregnancy for maternal and newborn outcomes. Cochrane Database Syst Rev. 2015;27(10):CD008666.

3. Bruins M, Kraemer K. Public health programmes for vitamin a deficiency control. Community Eye Health. 2013;26(84):69-70.

4. Imdad A, Mayo-Wilson E, Herzer K, Bhutta ZA. Vitamin a supplementation for preventing morbidity and mortality in children from six months to five years of age. Cochrane Database Syst Rev. 2017;11(3):CD008524.

5. Imdad A, Yakoob MY, Sudfeld C, Haider BA, Black RE, Bhutta ZA. Impact of vitamin a supplementation on infant and childhood mortality. BMC Public Health. 2011;S20. https://doi.org/10.1186/1471-2458-11-S3-S20.

6. West KP, Wu LS, Ali H, Klemm RDW, Edmond KM, Hurt L, et al. Early neonatal vitamin a supplementation and infant mortality: an individual participant data meta-analysis of randomised controlled trials. Arch Dis Child. 2019:104(3):217-26.

7. World Health Organization and Food and Agriculture Organization of the United Nations. Vitamin and mineral requirements in human nutrition. 2nd ed. Geneva: WHO; 2004

8. Stoltzfus RJ, Underwood BA. Breast-milk vitamin a as an indicator of the vitamin a status of women and infants. Bull World Health Organ. 1995;73(5): 703-11.

9. Oliveira JM, Allert R, East CE. Vitamin a supplementation for postpartum women. Cochrane Database Syst Rev. 2016;25(3):CD005944.

10. Gogia S, Sachdev HS. Maternal postpartum vitamin a supplementation for the prevention of mortality and morbidity in infancy: a systematic review of randomized controlled trials. Int J Epidemiol. 2010;39(5):1217-26.

11. UNAIDS. Global HIV \& AIDS statistics - 2019 fact sheet. Accessed from: https://www.unaids.org/sites/default/files/media_asset/UNAIDS_FactSheet en.pdf. Accessed on: Aug 22, 2019.

12. UNAIDS. Global HIV \& AIDS statistics - 2012 fact sheet. Accessed from: http://files.unaids.org/en/media/unaids/contentassets/documents/ epidemiology/2012/gr2012/20121120_FactSheet_Global_en.pdf. Accessed on: Aug 22, 2019.

13. de Pee S, Semba RD. Role of nutrition in HIV infection: review of evidence for more effective programming in resource-limited settings. Food Nutr Bull. 2010;31(S4):S313-44.

14. Singhal $\mathrm{N}$, Austin J. A clinical review of micronutrients in HIV infection. J Int Assoc Phys AIDS Care. 2002; (2):63-75.

15. World Health Organization. Antiretroviral therapy for HIV infection in infants and children: towards universal access: recommendations for a public health approach, 2010 revision. Geneva: World Health Organization; 2010.

16. Friis $\mathrm{H}$, Gomo E, Koestel P, Ndhlovu P, Nyazema N, Krarup H, et al. HIV and other predictors of serum beta-carotene and retinol in pregnancy: a crosssectional study in Zimbabwe. Am J Clin Nutr. 2001;73(6):1058-65.

17. Mulu A, Kassu A, Huruy K, Tegene B, Yitayaw G, Nakamori M, et al. Vitamin a deficiency during pregnancy of HIV infected and non-infected women in tropical settings of Northwest Ethiopia. BMC Public Health. 2011;11:569. https://doi.org/10.1186/1471-2458-11-569.

18. Moodley D, Moodley J, Coutsoudis A, Coovadia HM, Gouws E. Vitamin a levels in normal and HIV-infected pregnant women. S Afr Med J. 1998;88: 1029-32.

19. Semba RD, Miotti PG, Chiphangwi JD, Liomba G, Yang LP, Saah AJ, et al. Infant mortality and maternal vitamin a deficiency during human immunodeficiency virus infection. Clin Infec Dis. 1995;21(4):966-72.

20. Semba RD, Miotti PG, Chiphangwi JD, Dallabetta G, Yang LP, Saah AJ, et al. Maternal vitamin a deficiency and infant mortality in Malawi. J Trop Pediatr. 1998:44:232-4.

21. ICF International. Demographic and health survey: sampling and household listing manual. Calverton: ICF International; 2012. 
22. Huang Z, Liu Y, Qi G, Brand D, Zheng SG. Role of vitamin a in the immune system. J Clin Med. 2018;7(9):258.

23. Webb AL, Aboud S, Furtado J, Murrin C, Campos H, Fawzi WW, et al. Effect of vitamin supplementation on breast milk concentrations of retinol, carotenoids, and tocopherols in HIV-infected Tanzanian women. Eur J Clin Nutr. 2009;63(3):332-9.

24. Grilo EC, Lima M, Cunha L, Gurgel C, Clemente HA, Diemenstein R. Effect of maternal vitamin A supplementation on retinol concentration in colostrumEfeito da suplementação materna com vitamina A sobre a concentração de retinol no colostro. J Pediatr. 2015;91(1):81-6.

25. Wiysonge CS, Ndze VN, Kongnyuy EJ, Shey MS. Vitamin a supplements for reducing mother-to-child HIV transmission. Cochrane Database Syst Rev. 2017;2017(9):CD003648.

26. The WHO/CHD Immunization-Linked Vitamin A Group. Vitamin a supplementation of women postpartum and of their infants at immunization alters breast milk retinol and infant vitamin a status. J Nutr. 2002;132(11):3243-8

27. Bhaskaram P, Balakrishna N, Nair KM, Sivakumar B. Vitamin a deficiency in infants: effects of postnatal maternal vitamin a supplementation on the growth and vitamin a status. Nutr Res. 2000;20(6):769-78.

28. Rice AL, Stoltzfus RJ, de Francisco A, Chakraborty J, Kjolhede CL, Wahed MA. Maternal vitamin a or beta-carotene supplementation in lactating Bangladeshi women benefits mothers and infants but does not prevent subclinical deficiency. J Nutr. 1999;129(2):356-65.

29. Fawzi WW, Msamanga Gl, Wei R, Spiegelman D, Antelman G, Villamor E, et al. Effect of providing vitamin supplements to human immunodeficiency virus-infected, lactating mothers on the child's morbidity and CD4+ cell counts. Clin Infect Dis. 2003;36(8):1053-62.

30. Choi Y, El Arifeen S, Mannan I, Rahman SM, Bari S, et al. Can mothers recognize neonatal illness correctly? Comparison of maternal report and assessment by community health workers in rural Bangladesh. Tropical Med Int Health. 2010;15(6):743-53.

\section{Publisher's Note}

Springer Nature remains neutral with regard to jurisdictional claims in published maps and institutional affiliations.

Ready to submit your research? Choose BMC and benefit from:

- fast, convenient online submission

- thorough peer review by experienced researchers in your field

- rapid publication on acceptance

- support for research data, including large and complex data types

- gold Open Access which fosters wider collaboration and increased citations

- maximum visibility for your research: over $100 \mathrm{M}$ website views per year

At $\mathrm{BMC}$, research is always in progress.

Learn more biomedcentral.com/submissions 